\title{
MAPEAMENTO DOS OBJETOS DE APRENDIZAGEM COM A TEMÁTICA SUSTENTABILIDADE EM UM PORTAL DO MEC
}

\section{MAPPING OF THE LEARNING OBJECTS WITH THE THEME SUSTAINABILITY IN A MEC PORTAL}

\section{Guilherme Philippe Garcia Ferreira, Dr. (UFPR) Adriano Heemann, Dr. (UFPR)}

\author{
Palavras Chave \\ Objetos de Aprendizagem; BIOE; Sustentabilidade
}

\section{Key Words}

Learning Objects; International Bank of Educational Objects; Sustainability

\section{RESUMO}

A evolução tecnológica, em contexto local e global, traz novas ferramentas e meios de suporte ao ensino. Assim, surgem os Objetos de Aprendizagem (OA), recursos educacionais que desmaterializados se alinham à temática da sustentabilidade por sua capacidade de reuso. Em 2008 é implementado pelo Ministério da Educação o Banco Internacional de Objetos Educacionais (BIOE), com objetivo de manter e promover o compartilhamento e desenvolvimento de recursos educacionais. Neste trabalho apresentamos conceitos básicos sobre os objetos de aprendizagem, realizamos um mapeamento oferecendo uma visão sistemática de quais recursos são atualmente disponibilizados no portal, quais os formatos de mídia destes recursos e, por fim, apontamos considerações a respeito do contexto do BIOE e sua relevância para o meio acadêmico. Finalmente, sugerimos que o BIOE pode ser melhor explorado por meio de políticas que auxiliem o desenvolvimento e compartilhamento de recursos educacionais.

\section{ABSTRACT}

The technological evolution, in local and global context, brings new tools and means of support to the teaching. Thus, Learning Objects $(O A)$ emerge, educational resources that are dematerialized are aligned to the sustainability theme because of their capacity for reuse. In 2008, the International Bank for Educational Objects (BIOE) is implemented by the Ministry of Education to maintain and promote the sharing and development of educational resources. In this work we present basic concepts about learning objects, we perform a mapping offering a systematic view of what resources are currently available in the portal, what media formats these resources and, finally, we consider considerations about the context of BIOE and its relevance to the academic milieu. We believe that BIOE should be better explored through policies that support the development and sharing of educational resources. 


\section{INTRODUÇÃO}

A educação, que antes era predominantemente presencial, atualmente se encontra em uma fase de significativa ampliação de possibilidades. Uma delas é a Educação a Distância (EaD) suportada por redes de computadores e pela web. Neste contexto, uma das preocupações no ensino é a conscientização dos aspectos ambientais que são impactados pela ação do ser humano. Como discorre Nobre:

A preocupação com o meio ambiente é a nova ordem mundial e instituições, governos e entidades não governamentais têm que lidar com a conscientização e racionalização e uso adequado da água, entre outros. No entanto, as possíveis soluções passam pelo estudo e aprendizado da importância do meio ambiente em todos os níveis escolares, começando já nas séries iniciais. (NOBRE et al., 2011, p. 194)

Para viabilizar este aprendizado existe uma demanda por recursos didáticos que sejam adequados para explorar esta temática nos mais diversos níveis de aprendizagem. Há também a necessidade de tornar sustentáveis estas ferramentas, através de práticas que facilitem a reutilização das informações em diferentes contextos e por múltiplos profissionais. Com a maior representatividade do EaD, o uso de elementos e processos de aprendizagem por meio da internet se tornou frequente e hoje faz parte do diálogo de docentes e discentes, inclusive no repensar a forma de ensino.

Neste meio, emerge o conceito de Objetos de Aprendizagem. O termo em inglês "Learning Objects" é provavelmente originário do Instituto de Engenheiros Eletrônicos e Eletricistas (Institute of Electrical and Electronic Engineers - IEEE):

Objetos de aprendizagem são definidos como qualquer entidade - digital ou não digital - que pode ser utilizada para o aprendizado, educação e treinamento. (IEEE/LTSC, 2002, tradução nossa).

No Brasil, o Banco Internacional de Objetos Educacionais "BIOE" (2017), disponibilizado no portal do Ministério da Educação (MEC), apresenta um catálogo de diversos recursos para educação.

Considerando que o portal é orgânico e muitos objetos de aprendizagem passam por processos de exclusão, atualização, adequação ou mesmo inserção, não fica claro quais recursos podem ser utilizados para explanar os conteúdos com a temática sustentabilidade. Neste trabalho, apresentamos conceitos básicos em relação aos objetos de aprendizagem, realizamos um mapeamento oferecendo uma visão sistemática sobre os recursos atualmente disponibilizados no portal, os seus formatos de mídia e, por fim, apontamos considerações sobre o contexto do BIOE e sua relevância para o meio acadêmico.

\section{OBJETOS DE APRENDIZAGEM}

Os Objetos de Aprendizagem (OA) são recursos importantes para o desenvolvimento do ensino em contextos que extrapolam a sala de aula. Seu uso vinculado ao cenário digital permite o acesso a elementos educacionais limitados apenas pelo sustentáculo tecnológico. Como aponta Ferreira et al. $(2015$, p. 2):

Até o século XIX, as atividades de ensino e aprendizagem foram vinculadas principalmente a ambientes físicos, onde docente e discente mantêm um contato direto para troca de informações. Técnicas como o uso de apostilas, cartas e de vídeos surgiram com o objetivo de facilitar e promover o aprendizado à distância e até hoje são implementadas como alternativa de acesso ao conhecimento. Posteriormente, a redução de custos e o incremento de novas tecnologias permitiu a inclusão da informática no cotidiano viabilizando uma nova forma de distribuição de conteúdo, a informação digital com acesso global.

Embora primordial para a compreensão histórica, a definição dos OA apresentada por IEEE/LTSC (2002) pode ser questionada por sua amplitude. Apesar disso, é certo que os $O A$ desempenham papel de grande importância no contexto educacional. De acordo com Wiley (2002, p. 13, tradução nossa), "os OA são elementos de um novo tipo de instrução fundamentada no paradigma da orientação por objetos da ciência da computação". Isto é, trata-se de elementos ou componentes instrucionais que podem ser reutilizados em diferentes contextos de aprendizagem. Por sua finalidade de reuso, os OA permitem que professores e educadores tenham acesso a elementos educacionais desenvolvidos por pares e façam uso destes diretamente ou na construção de novos conteúdos educacionais. Este contexto é explorado por Bratina et al. (2002, s/p. tradução nossa), ao expor que: 
Seria insensato que cada professor escrevesse seu próprio livro didático. Similarmente, não é admissível que cada professor tenha de desenvolver todos os objetos de aprendizagem para um curso. A reusabilidade de objetos de aprendizagem, oferece uma forma eficiente de facilitar o ensino de conceitos comumente abordados, procedimentos, aplicações e habilidades; é possível re-adaptar alguns objetos de aprendizagem para diferentes tipos de usuários.

Mas a função de reuso dos $\mathrm{OA}$, quando observado o contexto da disponibilidade do conteúdo para utilização por pares, ainda não alcançou uma base sólida. A complexidade dos OA criados, as diversas granulidades da informação e os variados repositórios fazem com que ainda seja complexa a obtenção e localização rápida de conteúdo educacional. Essa situação muitas vezes promove a replicação de OA já desenvolvidos. Para dirimir esta problemática, é comum a adoção de padrões de metadados e a indexação deste conteúdo em portais como o oferecido pelo MEC. Neste sentido, Braga (2015, p. 12) discorre:

[.] quando bem utilizados, os OAs (Objetos de Aprendizagem) podem ser grandes aliados do processo educativo. É necessário, para isso, que o professor tenha clareza dos objetivos que deseja alcançar e, em seguida, pesquise, selecione e defina boas estratégias de utilização dos OAs em suas aulas, de forma a atender aos seus objetivos.

Portanto, os alcances dos objetivos discentes estão vinculados também à localização de recursos adequados ao que se pretende lecionar. Braga (2015, p. 15) identifica diferentes formatos destes recursos educacionais:

- Imagem: de acordo com o Dicionário Aurélio online, imagem é a "representação de uma pessoa ou coisa". Uma imagem digital pode ser utilizada para apoiar a aprendizagem, e devido a isso é considerada como um tipo de OA.

- Áudio: Um áudio é uma faixa do espectro reservada ao som, em contraposição ao vídeo (Dicionário Aurélio online). Um áudio pode atuar sozinho como um objeto de aprendizagem desde que seja utilizado para ensino.

- Vídeo: denomina-se vídeo uma gravação de imagens em movimento ou uma animação composta por fotos sequenciais que resultam em uma imagem animada (Stop-motion). Um vídeo utilizado para apoiar a aprendizagem é considerado um OA. Animações: a palavra Animação vem do latim "Anima", que significa "Alma" ou "Sopro Vital". Portanto, pode-se dizer que animação significa "dar vida" a objetos estáticos, que podem ser imagens, textos etc.

O BIOE (2017) aborda estes recursos didáticos de forma mais ampla e classifica os objetos por nível de educação, modalidade de ensino e em formatos de mídia:

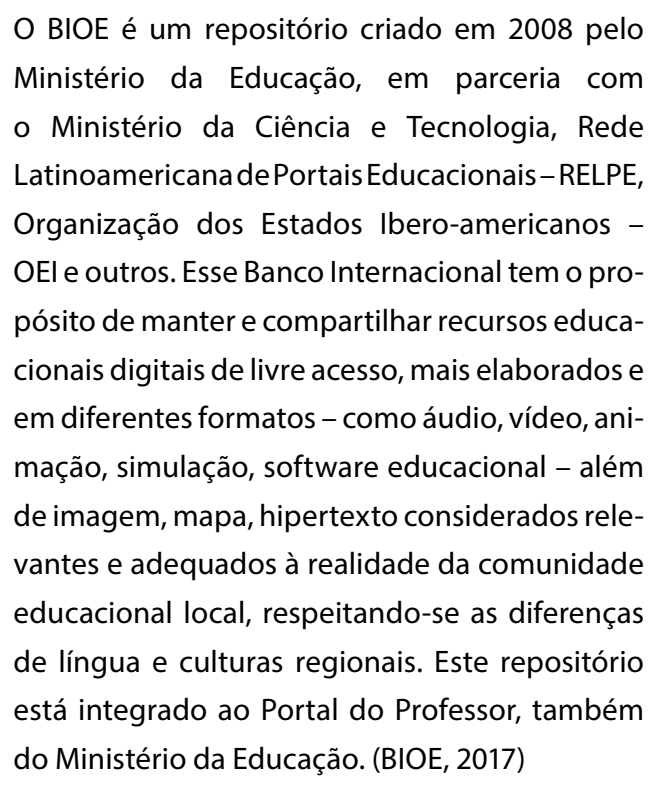

Como explanado, o BIOE não se limita a conteúdos na língua portuguesa e, portanto, seus recursos devem ser filtrados conforme o objetivo da aprendizagem. Na sequência deste documento realizamos um mapeamento de quais recursos podem ser localizados através deste portal.

\section{MAPEAMENTO DOS RECURSOS DISPONÍVEIS}

Para identificar os recursos do BIOE (2017), foi realizado o acesso ao portal no dia 20 de novembro de 2017. Na referida data, o BIOE retornava 19.842 objetos publicados, sendo que deste total 174 estavam em processo de avaliação por pares ou aguardando autorização dos autores para publicação. Filtrando estes recursos para apenas aqueles em língua portuguesa, o BIOE indicava o montante de 10.198 objetos disponíveis.

Não solicitando acesso diferenciado ou quaisquer tipos de vínculos institucionais para realizar pesquisas ou utilizar os objetos, o BIOE atua tanto como indexador e avaliador quanto como repositor de conteúdo. O acesso a página principal do BIOE ocorre por meio de qualquer navegador web conectado a uma rede ativa. Na página inicial são apresentadas as diferentes funcionalidades do BIOE (Figura 1). 
Figura 1: Tela inicial do BIOE de objetos.

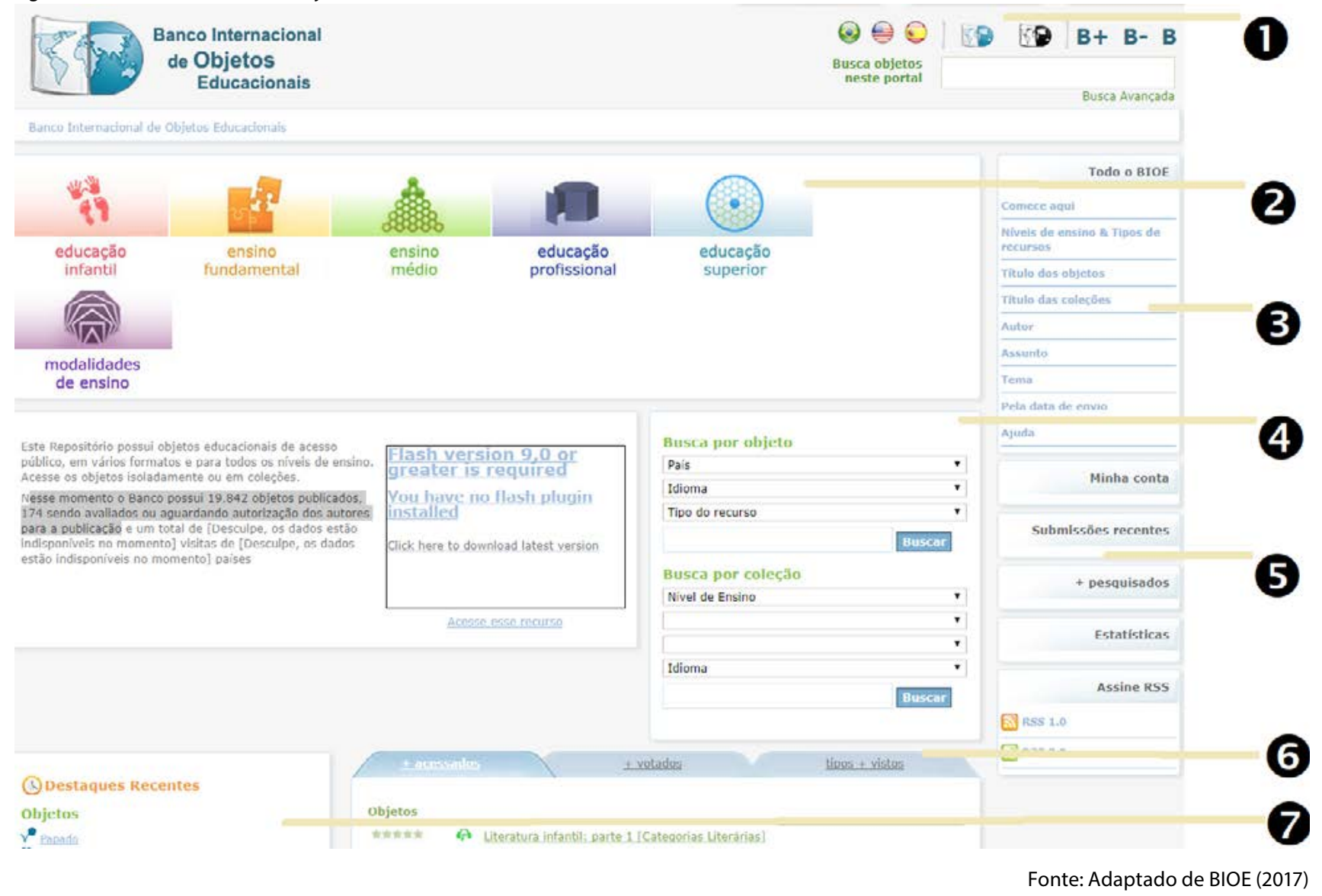

No Campo 1 são disponibilizados ajustes para utilização do BIOE em português, inglês ou espanhol. Também são contemplados menus para acessibilidade com diferentes contrastes visuais e possibilidade de alteração no caminho da fonte. O Campo 2 apresenta ícones relativos aos níveis de conhecimento dos objetos, educação infantil, ensino fundamental, médio, profissional ou superior, assim como as modalidades de ensino que após acesso permite filtragem por educação de jovens e adultos e educação escolar indígena. O Campo 4 mostra menu de acesso à pesquisa, enquanto o Campo 5 possibilita o registro do usuário, a submissão de objetos e também estatísticas sobre o número de acessos e principais pesquisas. O Campo 6 revela os destaques em objetos e coleções.Por fim, o campo 7 oferece listagem dos objetos mais acessados, votados e vistos.

Através do Campo 4 utilizamos o menu de busca por objeto, sendo que no espaço de seleção de país e tipo de recurso nenhuma alteração foi realizada, em Idioma selecionamos português e como palavras-chave usamos: sustentabilidade; sustentável e eficiência energética. Os resultados desta pesquisa são apresentados na sequência.

\section{RESULTADOS}

Como mencionado anteriormente, o BIOE classifica os objetos por níveis educacionais e também através do formato de mídia: Animação/Simulação, Imagem, Áudio, Mapa, Experimento Prático, Software Educacional, Hipertexto ou Vídeo. Para cada um destes tipos o BIOE apresenta um ícone específico, como ilustra a Figura 2.

Figura 2: Ícones do BIOE para as mídias educacionais.

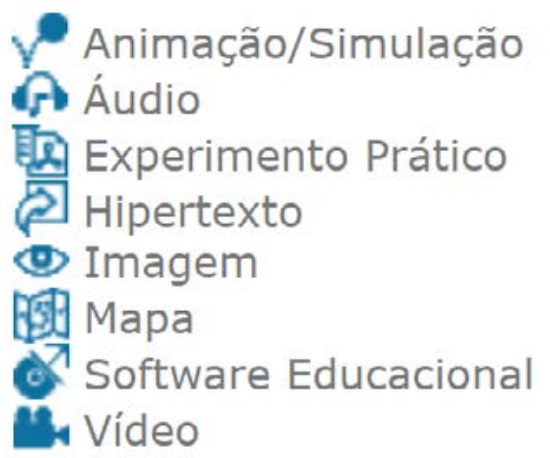

Fonte: Adaptado de BIOE (2017)

É importante que o pesquisador observe estes ícones, pois durante os resultados de pesquisa não são 
apresentadas as descrições textuais dos formatos de mídia, apenas o ícone junto à descrição do recurso localizado, com título, autoria e tamanho do arquivo. Na sequência, expomos os resultados da pesquisa realizada em 20 de novembro de 2017 a partir das palavras-chave: sustentabilidade; sustentável e eficiência energética.

\subsection{Resultados do termo sustentabilidade}

Para o termo sustentabilidade foram produzidos 27 resultados. Discriminados por ano de indexação ao portal; (3) 2008; (6) 2009; (7) 2010; (6) 2011; (4) 2012 e (1) 2013. Conforme o Quadro 1:

Quadro 1: Resultados do termo sustentabilidade.

\begin{tabular}{|c|c|c|}
\hline $\begin{array}{l}\text { Animação/ } \\
\text { Simulação }\end{array}$ & & $\begin{array}{l}\text { (1) - Eletricidade: O futu- } \\
\text { ro da eletricidade. }\end{array}$ \\
\hline Áudio & & $\begin{array}{l}\text { (8) - Aquífero Guarani } \\
\text { - recursos hídricos; } \\
\text { Almanaque sonoro de quí- } \\
\text { mica - Lixo Urbano: descar- } \\
\text { te e reciclagem de materiais } \\
\text { - Parte 1.1; Almanaque } \\
\text { sonoro de química - Lixo } \\
\text { Urbano: descarte e recicla- } \\
\text { gem de materiais - Parte } \\
\text { 1; Almanaque sonoro de } \\
\text { química - Cosméticos - } \\
\text { Parte 1; Almanaque sonoro } \\
\text { de química - Cosméticos } \\
\text { - Parte 1.1; Evolução } \\
\text { cultural do ser humano - } \\
\text { Parte l; Evolução cultural } \\
\text { do ser humano - Parte II; } \\
\text { Minhocuçu: Conservação e } \\
\text { Sustentabilidade. }\end{array}$ \\
\hline $\begin{array}{l}\text { Experimento } \\
\text { Prático }\end{array}$ & & $\begin{array}{l}\quad \text { (5) - Atividade micro- } \\
\text { biana do solo: respiração } \\
\text { do solo; Papel artesanal - } \\
\text { atividade 1: Lixo, problema } \\
\text { causado por todos nós; } \\
\text { Reciclando: Confecção de } \\
\text { papel reciclado e sa- } \\
\text { bão - Aula 1; Reciclando } \\
\text { Confecção de papel } \\
\text { reciclado e sabão - Aula 2; } \\
\text { Reciclando: Confecção de } \\
\text { papel reciclado e sabão - } \\
\text { Aula 3. }\end{array}$ \\
\hline
\end{tabular}

\begin{tabular}{|c|c|c|}
\hline Imagem & $\begin{array}{l}\text { (2) - Telhado verde; } \\
\text { Rotulagem ambiental. }\end{array}$ \\
\hline Vídeo & $\begin{array}{l}\text { (11) - A história das } \\
\text { coisas; Reciclagem [Aula } \\
\text { lá fora]; Povos da floresta } \\
\text { [Sala de convidados]; Aula } \\
\text { inaugural da ENSP [Canal } \\
\text { aberto]; Gabrielle Brandão } \\
\text { - Palestra em Cotia - Parte I; } \\
\text { Gabrielle Brandão - Palestra } \\
\text { em Cotia-Parte II; Cidades } \\
\text { sustentáveis [Sala de convi- } \\
\text { dados]; O que é sustentabi- } \\
\text { lidade; Eficiência energética: } \\
\text { desafios e oportunidades; O } \\
\text { uso de resíduos na cons- } \\
\text { trução civil; Reciclando: } \\
\text { Confecção de papel recicla- } \\
\text { do e sabão - Aulas 1, 2 e 3 }\end{array}$ \\
\hline
\end{tabular}

Fonte: Dados do BIOE (2017)

Não foram identificados resultados em formato hipermídia, mapa e software educacional.

\subsection{Resultados do termo sustentável}

Para o termo sustentável foram produzidos 116 resultados. Discriminados por ano de indexação ao portal; (43) 2008; (15) 2009; (15) 2010; (23) 2011; (16) 2012 e (4) 2013. Conforme o Quadro 2: 
Quadro 2: Resultados do termo sustentável.

\begin{tabular}{|c|c|}
\hline $\begin{array}{l}\text { Animação/ } \\
\text { Simulação }\end{array}$ & $\begin{array}{l}\quad \text { (14) - Até as últimas con- } \\
\text { sequências; A3P - Agenda } \\
\text { Ambiental na Administração } \\
\text { Pública; Puzzle dos re- } \\
\text { cursos naturais; Como } \\
\text { é feita a ponte sobre os } \\
\text { rios; Sustentação de uma } \\
\text { barra; Diagrama de forças; } \\
\text { Laminário virtual: Tecidos de } \\
\text { sustentação e revestimento; } \\
\text { Qual é a palavra? Problemas } \\
\text { ambientais brasileiros e } \\
\text { desenvolvimento sustentá- } \\
\text { vel: uma relação possível?; } \\
\text { Qual é a palavra? A diversi- } \\
\text { dade ameaçada; Mysterium } \\
\text { Cosmographicum; } \\
\text { Mecanismos de formação } \\
\text { de chuvas ácidas e suas } \\
\text { consequências para o } \\
\text { ambiente natural; A física e } \\
\text { o cotidiano - Laboratório } \\
\text { virtual: O Fogão Solar; } \\
\text { Energia Nuclear e Impacto } \\
\text { Ambiental - Geração de } \\
\text { Energia; Mecânica - Física e } \\
\text { tecnologia do vôo. }\end{array}$ \\
\hline Áudio & $\begin{array}{l}\quad \text { (11) - Cuide bem do livro; } \\
\text { Fim de férias; O desen- } \\
\text { volvimento sustentável; } \\
\text { Professor meio ambiente } \\
\text { parte 07: as matas e as } \\
\text { florestas; Caminhos para } \\
\text { uma agricultura de base } \\
\text { ecológica [Prosa rural]; } \\
\text { Etnoecologia; Almanaque } \\
\text { Sonoro de Química - } \\
\text { Poluição Atmosférica - } \\
\text { Parte 3; Almanaque Sonoro } \\
\text { de Química - Poluição } \\
\text { Atmosférica - Parte 3.1; A } \\
\text { viagem de Kemi - Lixo ur- } \\
\text { bano: Descarte e reciclagem } \\
\text { de materiais - Mobilização } \\
\text { sustentável; As árvores; } \\
\text { Energia Elétrica - Quem } \\
\text { Sustenta Essa Ideia. }\end{array}$ \\
\hline
\end{tabular}

\begin{tabular}{|c|c|c|}
\hline $\begin{array}{c}\text { Experimento } \\
\text { Prático }\end{array}$ & & \begin{tabular}{l}
\multicolumn{1}{|c}{ (18) - Evolução dos } \\
palitos; Ilusões de Óptica - \\
Olho Humano; Equilíbrio; \\
Polias; Propagação de calor \\
por convecção - 2; Canhão \\
de sal de frutas 1; Canhão \\
de borrachinha; Suporte de \\
ar; O ovo engarrafado; Solos \\
- atividade 1: Descobrindo \\
paisagens; Ovo flutuante; \\
Corpo humano - ativida- \\
de 3: Articulações; Plantas \\
- atividade 5: Podemos \\
reproduzir um ecossistema?; \\
Brincando com lixo: robô; \\
Prisma de água; A física e o \\
cotidiano - Experimentos \\
Educacionais : O Fogão \\
Solar; Tensão superficial; Um \\
golpe de vara.
\end{tabular} \\
\hline Imagem & (U) & $\begin{array}{l}\text { (2) - Intestino delgado; } \\
\text { Rotulagem ambiental. }\end{array}$ \\
\hline Hipertexto & $\sqrt{8}$ & $\begin{array}{l}\text { (1) - Botânica - tecidos } \\
\text { vegetais. }\end{array}$ \\
\hline $\begin{array}{c}\text { Software } \\
\text { Educacional }\end{array}$ & & $\begin{array}{l}\text { (1) - Ciclo de Vida em } \\
\text { Vegetais. }\end{array}$ \\
\hline Vídeo & & \begin{tabular}{|l}
\multicolumn{1}{|c}{ (69) - Você sabia? } \\
Guardiões da Biosfera - \\
Mata Atlântica - Espécie \\
Bandeira; (VSGB-MA) - \\
Jabuticaba; (VSGB-MA) - \\
Dossel; (VSGB-MA) - Erva- \\
mate; (VSGB-MA) - Tijuca; \\
(VSGB-MA) - Recorde; \\
(VSGB-MA) - Pau Brasil; \\
(VSGB-MA) - Piaçava; (VSGB) \\
- Cerrado - Ocupação; \\
(VSGB-CE) - Savana \\
Brasileira; (VSGB): cerrado: \\
bichos em extinção; (VSGB- \\
CE) - Localização; (VSGB-CE) \\
- Parques Nacionais; (VSGB- \\
CE) - Raízes das árvores; \\
(VSGB-CE) - Veredas; (VSGB- \\
CE) - Plantas endêmicas; \\
(VSGB-CE) - Povo Kalunga; \\
(VSGB-CE) - Biodiversidade; \\
(VSGB-CE) - Buriti;
\end{tabular} \\
\hline
\end{tabular}




\begin{tabular}{|c|c|}
\hline Vídeo & 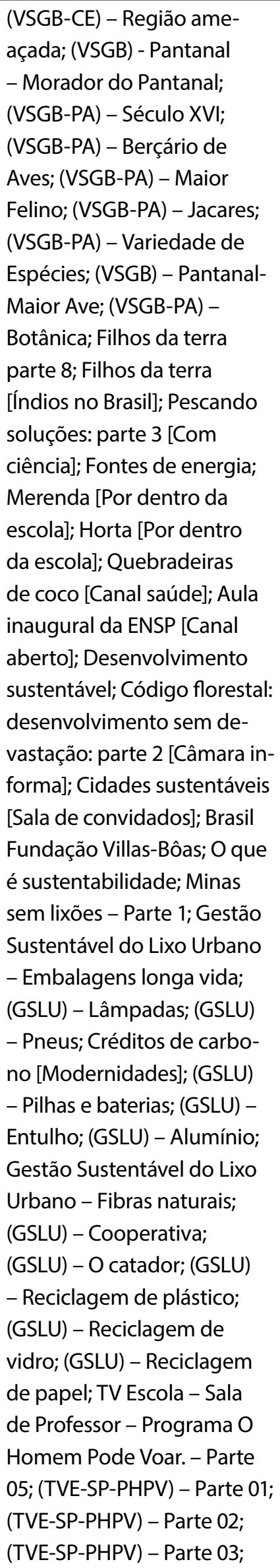 \\
\hline
\end{tabular}

\begin{tabular}{|l|l|l|}
\hline & $\begin{array}{l}\text { (TVE-SP-PHPV) - Parte 04; } \\
\text { (TVE-SP-PHPV) - Parte 06; } \\
\text { (TVE-SP-PHPV) - Parte } \\
\text { Vídeo } \\
\text { 08; TV Escola - Sala de } \\
\text { Professor - Programa A } \\
\text { maestria do voo - Parte 05; } \\
\text { (TVE-SP-PAMV) - Parte 01; } \\
\text { (TVE-SP-PAMV) - Parte 02; } \\
\text { (TVE-SP-PAMV) - Parte 03; } \\
\text { (TVE-SP-PAMV) - Parte 04; } \\
\text { The four forces of flight; Que } \\
\text { a força esteja com você. }\end{array}$ \\
\hline
\end{tabular}

Fonte: Dados do BIOE (2017)

Não foram identificados resultados no formato mapa.

\subsection{Resultados do termo eficiência energética}

Para o termo eficiência energética foram produzidos 10 resultados. Discriminados por ano de indexação ao portal; (2) 2008; (7) 2009 e (1) 2011. Conforme o Quadro 3:

Quadro 3: Resultados do termo eficiência energética.

\begin{tabular}{|c|c|}
\hline $\begin{array}{l}\text { Animação/ } \\
\text { Simulação }\end{array}$ & $\begin{array}{l}\quad \text { (4) - Transmitância } \\
\text { versão } 1.0 \text { (beta); Analysis } \\
\text { 1.5; Analysis CST; Analysis } \\
\text { SOL-AR. }\end{array}$ \\
\hline $\begin{array}{c}\text { Software } \\
\text { Educacional }\end{array}$ & $\begin{array}{l}\text { (5) - Umidus; Netuno; } \\
\text { AvalCon-RIO; Luz do sol; } \\
\text { Psychros. }\end{array}$ \\
\hline Vídeo & $\begin{array}{l}\quad \text { (1) - Eficiência } \\
\text { energética: desafios e } \\
\text { oportunidades. }\end{array}$ \\
\hline
\end{tabular}

Fonte: Dados do BIOE (2017)

Não foram identificados resultados no formato imagem, áudio, mapa, experimento prático e hipertexto.

\subsection{Resultados Consolidados}

No total foram produzidos 153 resultados. Discriminados por ano de indexação ao portal; (48) 2008; (28) 2009; (22) 2010; (30) 2011; (20) 2012 e (5) 2013. O total desta pesquisa por formato de mídia é demonstrado no Quadro 4: 
Quadro 4: Resultados do termo eficiência energética.

\begin{tabular}{|c|c|c|c|c|c|}
\hline $\begin{array}{l}\text { Animação/ } \\
\text { Simulação }\end{array}$ & $y$ & 29 & Imagem & (D) & 4 \\
\hline Áudio & p & 19 & Mapa & B日 & $X$ \\
\hline $\begin{array}{c}\text { Experimento } \\
\text { Prático }\end{array}$ & 配 & 23 & $\begin{array}{c}\text { Software } \\
\text { Educacional }\end{array}$ & & 6 \\
\hline Hipertexto & 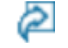 & 1 & Vídeo & & 81 \\
\hline
\end{tabular}

Fonte: Elaborado pelos autores (2017)

Como pode ser observado, não foram identificados recursos classificados como mapa no BIOE. Esta pesquisa por termos não elucida para qual nível educacional ou componente curricular os objetos se destinam. Para tanto, é necessário que o usuário efetue a pesquisa considerando campos avançados ou acessando estes objetos individualmente no BIOE. Por exemplo, ao realizar uma busca sobre o tema "papel artesanal" o usuário pode ter acesso a estes campos (Figura 3).

Figura 3: Descrição do objeto papel artesanal.

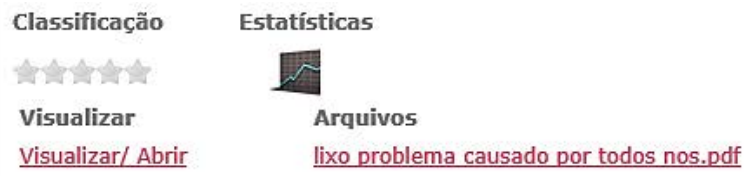

Clique aqui para baixar o pluain necessário para a visualizacão do recurso

\begin{tabular}{|c|c|}
\hline Redes Sociais: & 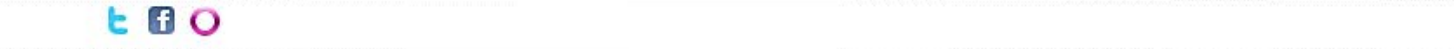 \\
\hline Título: & Papel artesanal - atividade 1: Lixo, problema causado por todos nós \\
\hline Tipo do recurso: & Experimento prático \\
\hline Objetivo: & Reconhecer o lixo como um problema sério do mundo atual e conscientizar sobre as nossas responsabilidades diante deste problema \\
\hline $\begin{array}{l}\text { Descrição do } \\
\text { recurso: }\end{array}$ & $\begin{array}{l}\text { Guia de experimentos que permite conscientizar sobre o que é lixo e suas causas à vida do planeta. Dessa forma, nota-se a necessidade } \\
\text { de reconhecer o lixo produzido e o destino deste ao sair das casas, assim como a importância em reciclar, fazendo a dassificação do tipo } \\
\text { de lixo que é encontrado e suas causas ao mundo }\end{array}$ \\
\hline Observação: & Experimento simples, com a utilização de materiais de baixo custo e de fácil obtenção \\
\hline $\begin{array}{l}\text { Componente } \\
\text { Curricular: }\end{array}$ & Educação Infantil::Natureza e sociedade \\
\hline Tema: & Educação Infantil::Natureza e sociedade::Objetos e processos de transformação \\
\hline Autor(es): & Passos, Evandro Ferreira \\
\hline Idioma: & Português (pt) \\
\hline País: & Brasil (br) \\
\hline $\begin{array}{l}\text { Fonte do } \\
\text { recurso: }\end{array}$ & Centro de Referência do Professor (CRP) - Universidade Federal de Viçosa \\
\hline $\begin{array}{l}\text { Endereço } \\
\text { eletrônico: }\end{array}$ & http://www.ufv.br/crp/Roteiros/Papel\%20Artesanal.pdf \\
\hline $\begin{array}{l}\text { Detentor do } \\
\text { direito autoral: }\end{array}$ & Parque da Ciência da Universidade Federal de Viçosa \\
\hline Licença: & $\begin{array}{l}\text { A licença desta obra encontra-se no próprio site, a qual proíbe utilizar estes roteiros de atividades com finalidades comerciais. É } \\
\text { permitido copiar, distribuir, exibir, traduzir e executar os roteiros de atividades disponibilizados, desde que seja dado crédito ao autor } \\
\text { Prof. Evandro Ferreira Passos e citado este "site" como fonte }\end{array}$ \\
\hline Submetido por: & Universidade Federal de São Carlos (UFSCAR) \\
\hline URI: & http://objetoseducacionais2.mec.gov.br/handle/mec/12007 \\
\hline Disponivel em: & Educacão Infantil: Natureza e sociedade: Experimentos Práticos \\
\hline
\end{tabular}


A tela de descrição dos objetos oferece informações relevantes ao usuário do site para que compreenda as características de cada um como, por exemplo, título, tipo do recurso, do objetivo educacional, a descrição dos recursos, as observações ao usuário, para qual componente curricular se destina a autoria do objeto, entre outros. Há ainda no canto inferior esquerdo a opção de visualizar os metadados do objeto, que são os registros codificados do objeto para sua identificação. Considerando o volume total produzido com esta pesquisa chegamos ao seguinte resultado: educação infantil ( 9 de 851); ensino fundamental (71 de 5068); ensino médio (67 de 10289), educação profissional (2 de 523); educação superior (26 de 9206); em modalidades de ensino, educação de jovens e adultos (1 de 312), educação escola indígena (0 de 15).

\section{ANÁLISE DOS RESULTADOS}

Neste mapeamento identificamos, por meio dos termos "sustentabilidade", "sustentável" e "eficiência energética", o total de 153 objetos educacionais. Estes recursos representam aproximadamente $1,5 \%$ do total de objetos disponibilizados no BIOE em língua portuguesa. Este percentual dado não pode ser interpretado imediatamente como uma baixa representatividade da temática no banco, já que tal julgamento demandaria uma pesquisa mais ampla com diferentes termos relativos à sustentabilidade. Entretanto, podemos supor que se trata de um indício de pouca demanda por estes objetos, ou de pouco interesse em seu desenvolvimento. Outro dado relevante desta pesquisa é a relação do ano de indexação com o volume de objetos produzidos, considerando o total de documentos identificados com o uso dos termos "sustentabilidade", "sustentável" e "eficiência energética", conforme ilustra o Gráfico 1.

Gráfico 1: Retorno total com os termos de pesquisa $X$ ano de indexação no BIOE

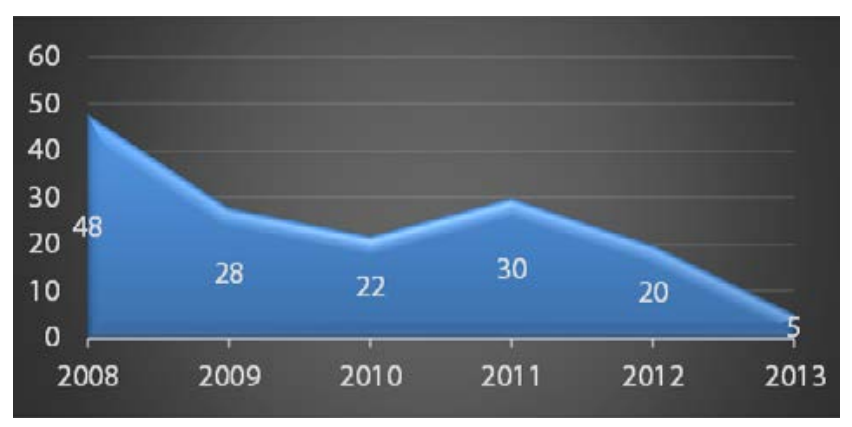

Fonte: Elaborado pelos autores (2017)

Este gráfico evidencia dois aspectos importantes: não houve, considerando os termos pesquisados, produção superior a 50 objetos de aprendizagem por ano desde a implementação do BIOE em 2008 e, após uma queda acentuada para apenas 5 OA em 2013, nenhum outro recurso foi indexado com os termos relacionados nesta pesquisa após o ano de 2013. Não fica claro o motivo de não haver $\mathrm{OA}$ indexados ao $\mathrm{BIOE}$, com os termos pesquisados, após o ano de 2013. Estes aspectos podem ser decorrentes de uma suposta modificação no vocabulário, uma baixa demanda pelo uso do $\mathrm{BIOE}$, do pouco incentivo para produção de objetos ou de uma demanda suprida com os objetos já indexados ao portal. Para avaliar melhor estes aspectos, aprofundamos a investigação. Os resultados são apresentados de modo sintetizado no Gráfico 2.

Gráfico 2: Objetos identificados x volume total na BIOE.

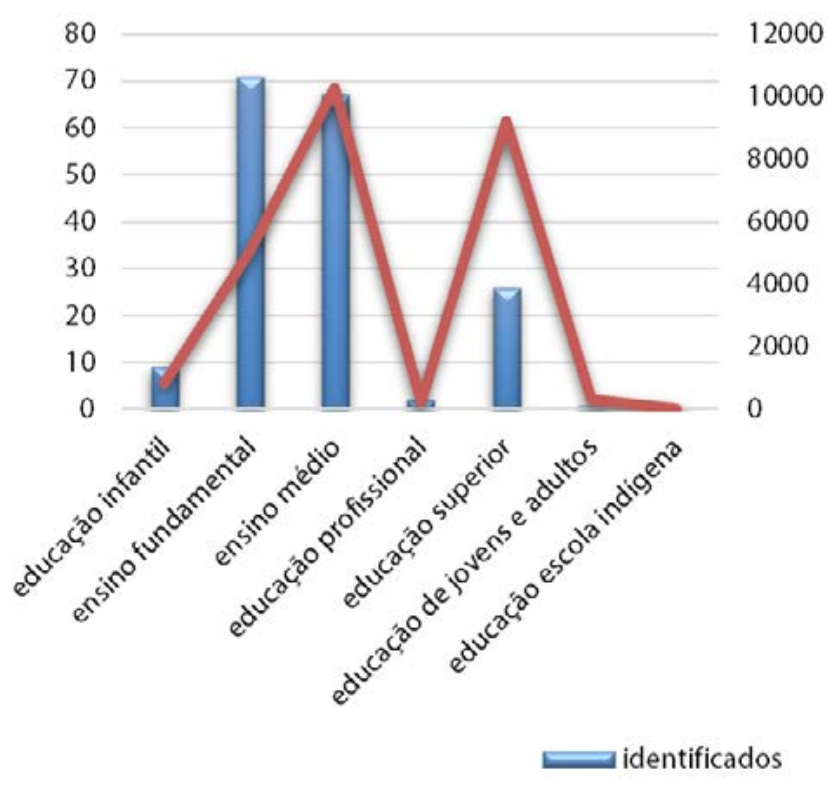

Fonte: Elaborado pelos autores (2017)

A suposição de que poderiam existir objetos suficientes para atender às demandas dos diferentes níveis educacionais é descartada como ilustra o gráfico. Observamos que apenas dois níveis de ensino demonstram volume de produção expressivos: o ensino fundamental e o ensino médio. Entretanto, com menos de $80 \mathrm{OA}$ para cada um deles e levando em consideração o volume total de recursos indexados, destaca-se o contraste entre os níveis principalmente na educação profissional, de jovens e adultos, indígena e infantil, que não possuem expressividade com os termos pesquisados. O Gráfico 3 traz uma representação que evidencia os formatos de mídias com maior volume de objetos. 
Gráfico 3: Objetos identificados, quantidades e percentual do volume total

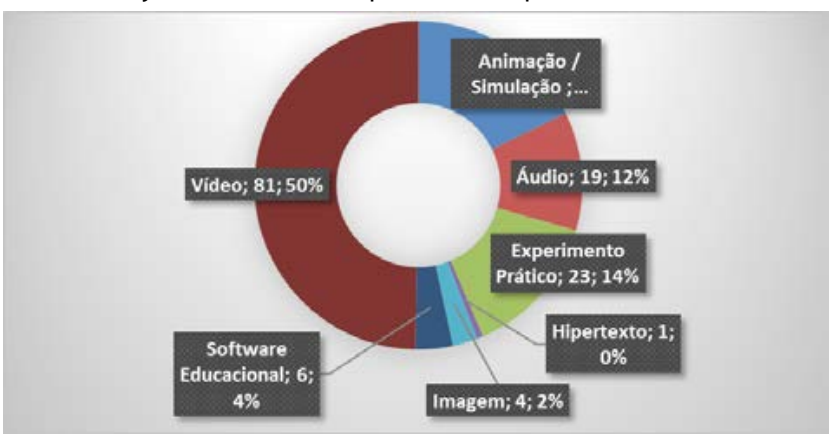

Fonte: Elaborado pelos autores (2017)

Identificamos 81 recursos em vídeo, 29 em animação ou simulação, 23 experimentos, 19 objetos em áudio, 6 softwares educacionais, 4 imagens, 1 hipertexto e não foram identificados resultados no formato mapa para os termos pesquisados. Já a partir desta análise inicial, observamos que o BIOE pode ter sido negligenciado por políticas pouco eficientes na manutenção e indexação de novos e atualizados OA.

Ao verificarmos os últimos recursos indexados ao BIOE, constatamos um importante contraste: desde 2015 não teriam sido adicionados novos documentos ao banco. Ora, a educação demanda sobretudo atualização. A falta de atualização dos recursos no BIOE nos parece um aspecto contrastante. A constante atualização de bancos de OA é considerado essencial por praticamente todos os estudiosos do assunto. No que se refere a equipes colaborativas e manutenção a longo prazo, Borba et al. esclarecem que:

\footnotetext{
[.] a construção do OA é realizada por meio da colaboração de três subequipes: a pedagógica, a tecnológica e a de design; buscando um objetivo em comum, cada uma contribuindo com sua especialidade. $E$, como a ideia principal na construção do OA é estender a sua utilização para vários projetos e vários contextos, pensar na preservação a longo prazo desses objetos é algo de grande relevância. (BORBA et al., 2015, p. 84)
}

Embora o BIOE tenha a missão de disponibilizar e promover o desenvolvimento de OA para práticas sustentáveis de compartilhamento de recursos de ensino e aprendizagem, na prática esta missão não tem sido cumprida.

\section{CONCLUSÕES}

Neste documento investigamos os OA como recursos educacionais no contexto da sustentabilidade devido aos aspectos de reuso e desmaterialização caracterizado pela imaterialidade dos objetos digitais e o armazenamento e distribuição através da rede de computadores. Recorremos aos seus conceitos básicos e sobre como podem ser compreendidos. Por meio de um estudo exploratório do Banco Internacional de Objetos de Aprendizagem (BIOA), portal vinculado ao MEC, utilizamos os termos "sustentável", "sustentabilidade" e "eficiência energética" para uma pesquisa básica que culminou em um diagnóstico importante.

O BIOE tem a missão de manter e compartilhar recursos educacionais digitais livres. Desde 2008 o portal chegou a disponibilizar 19.842 objetos. Atualmente outros 174 estão em processo de avaliação. Com a aplicação dos termos de busca, como filtros para localização de objetos específicos dentro do tema sustentabilidade, a oferta de recursos caiu para 153 OA. Com base nos dados levantados, concluímos que o potencial do BIOE para o ensino no Brasil é menosprezado desde sua criação no ano 2008, sobretudo devido a carência de atualização e disponibilização de OA. Pesquisas futuras poderiam se aprofundar nas causas desta situação e apontar ações para a sua superação.

\section{AGRADECIMENTOS}

Os autores agradecem à CAPES e ao CNPq pelo apoio na forma de bolsa de estudos e bolsa de produtividade em pesquisa.

\section{REFERÊNCIAS}

Banco Internacional de Objetos Educacionais - BIOE. Disponível em: <http://objetoseducacionais2.mec.gov. br/>. Acesso em: 27/11/2017.

BORBA, V. DA R.; SIEBRA, S. DE A.; GALINDO, M.; MACHIAVELLI, J. L.; GUSMÃO, C. M. G. Políticas de Formatos de Arquivos para Objetos de Aprendizagem: Preservação Digital no Saber Tecnologias Educacionais e Sociais. Informação \& Tecnologia, v. 2, n. 1, p. 80-97, 2015.

BRAGA, J. (ORG). Objetos de Aprendizagem Volume 1: introdução e fundamentos. Santo André: UFABC, 2015.

BRATINA, T. A.; HAYES, D.; BLUMSACK, S. L. Preparing Teachers To Use Learning Objects. The Technology Source, 2002. Disponível em: <http://technologysource. org/article/preparing_teachers_to_use_learning_objects/>. Acesso em: 27/11/2017. 
FERREIRA, G. P. G.; HEEMANN, A.; KUNTZ, V. H.; ULBRICHT, V. R. Compreensão de diretrizes de acessibilidade para criação de objetos de aprendizagem por meio de uma representação gráfica de síntese. In: C. R. Batista; R. de F. A. Obregon; V. R. Ulbricht; T. Morita (Orgs.); Hipermídia e interdisciplinaridade na geração de conhecimento. v. 1, p.100-134, 2015. São Paulo, SP, Brasil: Pimenta Cultural.

IEEE/LTSC. IEEE Standard for Learning Object Metadata. IEEE Std 1484.12.1-2002, 2002. Nova York, Estados Unidos: Institute of Electrical and Electronics Engineers. Disponível em: <http://ieeexplore.ieee.org/ stamp/stamp.jsp?tp=\&arnumber=1032843>. Acesso em: 27/11/2017.

NOBRE, I. A. M.; DO ROSÁRIO, K.; SIQUEIRA, A. L.; DO NASCIMENTO, E. L. Consciência ambiental: Objeto de aprendizagem como apoio ao ensino de meio ambiente. Brazilian Symposium on Computers in Education (Simpósio Brasileiro de Informática na Educação-SBIE). Anais. v. 1, 2011.

WILEY, D. A. Connecting learning objects to instructional design theory: A definition, a metaphor, and a taxonomy. The instructional use of learning objects. p.35, 2002. Agency for Instructional Technology. Disponível em: <http://www.reusability.org/read/chapters/wiley. doc>. Acesso em: 27/11/2017. 